\title{
A Move Analysis of Research Article Introduction Written by Indonesian Authors: The Case of Soft and Hard Sciences
}

\author{
Dian Setiawati ${ }^{1, *}$ Siti Nurzihan Nabilla ${ }^{1}$ Didi Suherdi ${ }^{1}$ Eri Kurniawan ${ }^{1}$ \\ Wawan Gunawan ${ }^{1}$ Arif Husein Lubis ${ }^{2}$

\begin{abstract}
${ }^{1}$ English Education Department, Indonesia University of Education
${ }^{2}$ Korean Education Department, Indonesia University of Education

*Corresponding author Email: diansetiawati@upi.edu
\end{abstract}

\begin{abstract}
In scholarly international publication, the introduction is often seen by journal reviewers as the pivotal place to assess the contribution of the research. Therefore, genre analyses of research article introduction keep being concerned by many researchers of English for academic purposes to generate eligible models of writing introduction section. However, much is still less explored regarding the way NNES authors rhetorically organize the introduction across disciplines. This study seeks to compare rhetorical moves and steps of introduction between soft and hard science research articles. Eight research articles were collected from Indonesian authors. Swales' (2004) revised model of Creating A Research Space was used in the top-down stage. The linguistic features of the moves were further scrutinized in the bottom-up stage. The findings showed that all introductions conformed to the model, exemplifying the three moves: Establishing a territory, establishing a niche, and presenting the present work; regardless of the discipline. In the step level, the introductions from the hard-science disciplines exhibited the statement of research questions or hypotheses and definitional clarifications while presenting their works more than those from the soft-science disciplines. Regarding the linguistic realizations, while the tense use was more conformed, passive form was more evident in the hard science introductions. This study reaches a conclusion that discipline considerably influences the priority in conveying the information within the research article introduction along with the linguistic realizations. Recommendations for the teaching of English for research publication purposes are also presented.
\end{abstract}

Keywords: Comparison, discipline, introduction, research article, rhetorical moves

\section{INTRODUCTION}

In academia, research articles (RAs) have been considered an important academic genre for scholars and researchers in expanding the knowledge across disciplines. Research articles are of great importance because they are the products of scientific, systematic, and objective inquiry (Tessuto, 2015). The ability to write an eligible research article has been more definitive than ever in line with the growing increase of academic seminars, workshops, discussions, and publications. A positive rate of international publication in particular can have an impact on the writers' financial prosperity and academic reputation as well as the institution's international recognition and contribution Chang and Kuo (2011), Kanoksilapatham (2005), Suherdi, Kurniawan and Lubis (2020). Hence, academic investigations on the writing of research articles keep being the central agenda among researchers of English for academic purposes.

The competence of writing eligible research articles is reflected on the quality of the research articles. Generally, good quality research articles should encompass three elements: novelty, rigorous research methods, and usefulness of the research results Stoller and Robinson (2013). The introduction plays a pivotal role in exhibiting the novelty of the research. The introduction is defined as a place for the authors to 
explain the research background, the statement of gap, and the objectives of the present research Swales (1986). The importance of researching the introduction pertains to the role of introduction as an indicator of measuring the contribution of the research in international publication (Samraj, 2002).

Genre-approach move analysis is considered helpful to construe the complexity of writing research article introduction. Move analysis is conceptualized as a textual method to explore the rhetorical organization of a particular genre. Rhetorical organization encompasses moves and steps (Swales, 1990, 2004). The moves and steps are determined by the linguistic features.

Ever since the seminal work of John Swales so-called Creating A Research Space in investigating research article introduction in 1981, some research has been conducted to reveal the complexity of writing research article introduction. Wannaruk and Amnuai (2015) examined the rhetorical organization of 60 journal article introductions in the field of Applied Linguistics. The results showed that a research article introduction fundamentally consists of background, problem identification, and objective. Suryani (2014) echoed with the previous research that all moves were obligatory in a corpus of five introductions in the field of Computer Engineering.

Stoller and Robinson (2013) conducted a comparative move analysis of research article introductions in the fields of Chemistry and Applied Linguistics. The findings demonstrated that no significant difference between both disciplines. The authors started the introduction with the statement of research context, followed by the identification of gap from the previous research. They ended the introduction by providing a brief description of their present research to address the research gap. A comparative move analysis was also done by Arsyad et al. (2016). They investigated the rhetorical structure of 400 Indonesian RA introductions from eight disciplines. By using their analysis model, no moves were found to be obligatory. While Move 1 Establishing shared background knowledge, Move 2 Establishing the research field, and Move 4 Announcing the present research were conventional, Move 3 Justifying the present research project was optional.

Although this issue has been quite extensively researched by previous scholars, little is still understudies regarding the textual evidence of how Indonesian authors from soft and hard sciences organize research article introduction rhetorically. Hence, this study aims to compare the rhetorical styles of Indonesian authors from soft and hard sciences in organizing their research article introductions. The reason for this is that the nature of science has its distinctive criteria for assessing the quality. Bazerman (1981) asserted that the harder sciences are believed to be more rigid in assessing the knowledge claim than the social sciences. It is no surprise that while hard sciences put a great concern on the strong research results, soft sciences rely mostly on the depth of arguments and writers' explanations of the research results. This differing nature of both sciences may influence the rhetorical organization of introduction. The following research questions guide this study.

1. How do Indonesian authors from soft and hard sciences rhetorically organize their research article introductions?

2. How are the rhetorical moves linguistically realized by both groups of authors?

\section{METHODS}

\subsection{Research Design}

This study was designed as a qualitative comparative study. Particularly, this study employed genre-approach move analysis to analyse the data (Baker, 2010; Hyland, 2009; Swales, 1990). The reason is that move analysis can capture the similarities and differences of rhetorical moves manifested in the research article introductions from soft and hard sciences written by Indonesian authors. This method also allows the researchers to record the linguistic features in the introduction from both groups of science.

\subsection{Data Sources}

A small corpus of eight introductions were taken as the main data. At first, forty lecturers (20 lecturers from soft science, 20 others from hard science) were selected from a public university in Bandung, Indonesia. Then, further selection process yielded only eight introductions from eight lecturers: two lecturers from Faculty of Language and Arts Education; two lecturers from Faculty of Social Science Education; two lecturers from Faculty of Mathematics and Natural Science Education; two lecturers from Faculty of Technology and Vocational Education. The reason for this is that the eight authors have already had an experience in publishing their papers in international journals.

\subsection{Data Collection}

First, the researchers asked for all authors' permission to be willing to have their papers analysed. Second, one best paper of each lecturer was selected from Google Scholar database. After all papers were downloaded, they were stored in a folder to ease the analysis process. Fourth, the researchers extracted the title page along with the introduction from the full-text article and saved it in a Word file. 


\subsection{Data Analysis}

A series of discussions was conducted online due to the pandemic Covid-19 situation. The first discussion session was done to determine the timeline for the analysis process. The second discussion session was done to synchronize the understanding of all researchers regarding the concept of genre analysis through move analysis and to explain Swales' (2004) revised model of Creating A Research Space (CARS) as the main analysis model. Two student researchers were recruited and assigned a task to analyse one research article introduction each to get them more accustomed with the analysis model. The third discussion session was done to check the results of the preliminary analysis. Some feedback was given directly to the student researchers' works. Afterwards, the researchers analysed the eight selected introductions independently.

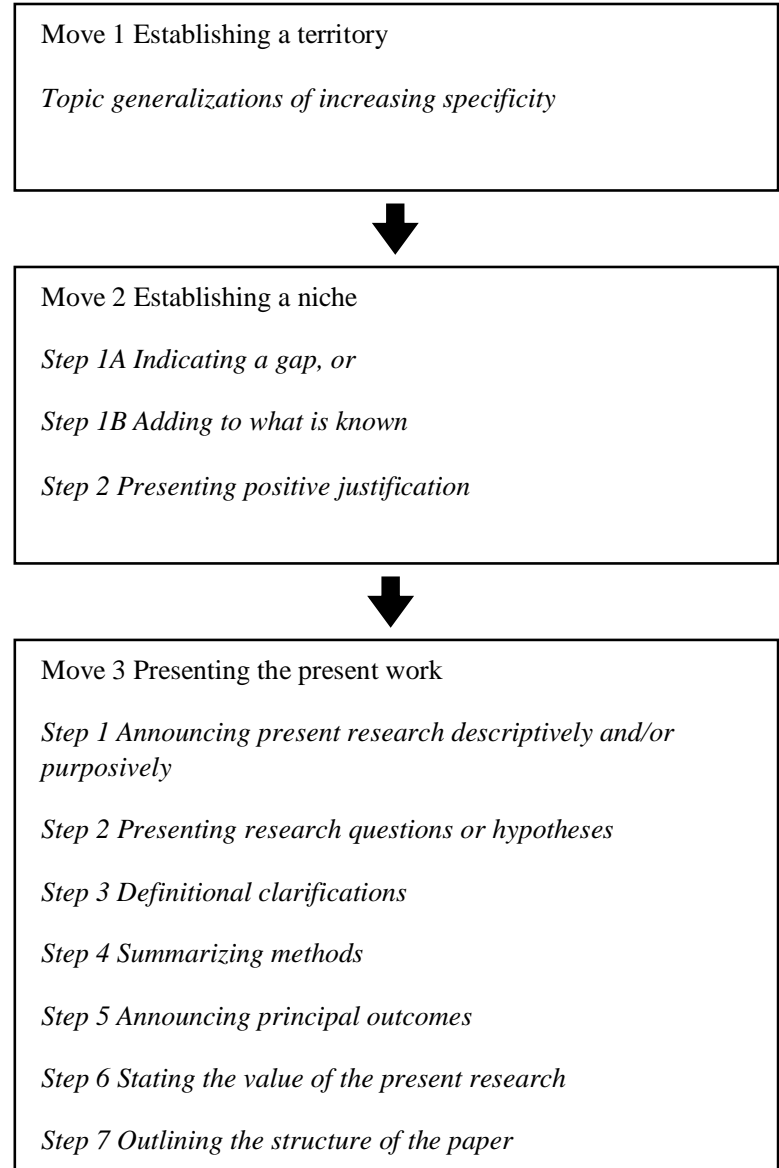

Figure 1 Revised model of Creating A research Space

The sentences were the units of analysis. The process started with breaking down the text into sentences. The sentences were moved into a table, consisting of three columns: sentence, move, and step. After that, the researchers read the title, abstract, and introduction first to get familiar with the research topic and the content. Each sentence was then labeled by a step, representing a particular purpose. The labelling process was based on the linguistic boundaries. All steps were categorized into the moves. Once the top-down analysis stage was done, the bottom-up analysis stage was done to further examine the linguistic features realized in the texts. The linguistic features include verb tense, sentence voice, the use of hedges, and citation styles. Once the second stage was finished, the results from soft and hard sciences were compared to obtain the similarities and differences. To maintain data trustworthiness, the results were checked by an expert in genre-approach move analysis.

\section{FINDINGS AND DISCUSSION}

This sub-section aims to delineate the rhetorical organization of research article introductions in soft and hard sciences. The linguistic realizations of the moves were described afterwards.

\subsection{Rhetorical Moves of the Introduction}

The analysis results showed that all introductions exemplified three-move configuration: Move 1 Establishing a territory, Move 2 Establishing a niche, and Move 3 Presenting the present work. Table 1 displays the percentage of occurrence for each move and step.

Table 1. Percentage of Occurrence for Each Move and Step

\begin{tabular}{ccc}
\hline $\begin{array}{c}\text { Move-step } \\
\text { Category }\end{array}$ & $\begin{array}{c}\text { Soft Science } \\
\boldsymbol{f ( \% )} \mathbf{n}=\mathbf{4}\end{array}$ & $\begin{array}{c}\text { Hard Science } \\
\boldsymbol{f}(\boldsymbol{\%}) \mathbf{n}=\mathbf{4}\end{array}$ \\
\hline Move 1 & 100 & 100 \\
Move 2 & 100 & 100 \\
Step 1A & 50 & 50 \\
Step 1B & 50 & 50 \\
Step 2 & 50 & 50 \\
Move 3 & 100 & 100 \\
Step 1 & 75 & 50 \\
Step 2 & 25 & 25 \\
Step 3 & 25 & 75 \\
Step 4 & 25 & 25 \\
Step 5 & 25 & 25 \\
Step 6 & 0 & 50 \\
Step 7 & 0 & 0 \\
\hline
\end{tabular}

\subsubsection{Move 1-Establishing a Territory}

This move occurred $100 \%$ in the soft- and hardscience introductions. This move was manifested to accomplish several communicative purposes. In the softscience research article introductions, the authors informed the significance of researching the topic. It was supported by positive justification from previous experts. Some other authors employed this move to locate the 
research topic as the centre of research intent by directly describing the concept of the topic being investigated.

Learning outcomes are the most important factor in learning, because they can describe the state of learners in understanding the material delivered by lecturers (RA1, Soft Science).

Limited lands and the dynamics of the urban community's activities cause competition in land uses and land-use changes (RA3, Soft Science).

Similarly, in the hard-science research article introductions, the authors tried to convince the readers that the research topic being investigated was important to be taken into account. Because hard-science studies were related to exact science, the authors informed the benefits of understanding the phenomenon. Another communicative purpose manifested in the introduction was to state the research significance by highlighting the negative effects if the phenomenon was not taken into account in real-life context.

The street lighting system is one of the most important facilities in cities. This system can increase the safety of road traffic participants and give pedestrians' sense of security on the other. (RA3, Hard Science).

Environmental stress may cause genetic diversity of the microbial community in that particular area to change by mutation, and genetic alteration will increase with the increasing of environmental stress. (RA1, Hard Science).

\subsubsection{Move 2 - Establishing a Niche}

This move also occurred $100 \%$ in the soft- and hardscience introductions. This move was intended to situate the contribution of the research to the body of knowledge in the field. There was no difference between the soft- and hard-science introductions in terms of the percentage of occurrence of all steps. The difference was more on the way the authors conveyed each step.

The present study would like to contribute to the existing research by focusing on the simultaneous influence of learning motivation and interest on college students' learning outcomes of language and art appreciation subject. (RA1, Step 1B, Soft Science)

It should also be noted that student satisfaction results not only from quality in teaching and learning, but it also comes from total student's experiences in their study (RA2, Step 1B, Hard Science)

The authors from soft science performed Step 1A Indicating a gap by questioning the consensus. The authors from hard science manifested the step by highlighting the dearth of research on the topic. Regarding Step 1B Adding to what is known, the authors from soft science informed the new knowledge that they offered from their research to enrich the existing body of knowledge. Meanwhile, the authors from hard science preferred to offer a new claim on the same issue justified by previous experts. Regarding Step 2 Presenting positive justification, the authors from both groups preferred to reinforce or make a concluding remark of what was already discussed before to justify the importance of their research.

\subsubsection{Move 3 - Presenting the Present Work}

Likewise, this move was considered obligatory $(100 \%$ of occurrence) in the soft- and hard-science introductions. Similarities and differences were identified in the step level. On the one hand, the authors from soft and hard sciences exemplified more interest to convey Step 1 Announcing present research descriptively and/or purposively than their counterparts. Additionally, they were less concerned with Step 2 Presenting research questions or hypotheses, Step 4 Summarizing methods, and Step 5 Announcing principal outcomes.

Based on the formulation of the problem which has been described previously, the purpose of this study was to: 1). Identify a potential tourist attraction based creative economy in the Cikole Village; 2). Analyse the readiness of Cikole Village as a rural tourism based creative economy; 3). Developing a pattern of rural tourism based creative economy in Cikole Village. (RA4, Step 1, Soft Science)

On the other hand, the authors from soft science did not considerably put great attention to Step 3 Definitional clarifications, as what the authors from hard science did (25\% and $75 \%$, respectively). The authors from hard science explicitly manifested Step 6 Stating the value of the present research in their introductions more than the authors from soft science (50\% and $0 \%$, respectively).

The redesign of street lighting refers to the standard of street lighting issued by the Indonesian National Standard, which in the Indonesian language, stands for Standard Nasional Indonesia (SNI). (RA3, Step 3, Hard Science)

Through this multimedia it is expected that the sense of sight and hearing play a full role in capturing all learning information and can improve student learning outcomes.... (RA4, Step 6, Hard Science)

The findings demonstrate that the Indonesian authors exhibit a three-move configuration, regardless of the nature of science. All research article introductions manifest Move 1 Establishing a territory, Move 2 Establishing a niche, and Move 3 Presenting the present work. No typical difference is identified caused by the differing science or discipline. This is in line with previous research (Arsyad et al., 2016; Stroller \& Robinson, 2013; Wannaruk \& Amnuai, 2015). This might be caused by the nature of research article introduction. This part is intended to clarify why the research topic is important to be investigated, what the concept of the research topic looks like, and what goals the research is going to achieve. Moreover, the authors are all lecturers 
in which they must have certain level of knowledge of academic writing obtained during their undergraduate and graduate studies, particularly in writing research article introduction.

There is a slight difference between soft and hard sciences in the step level. The authors from hard sciences convey Step 3 Definitional clarifications and Step 6 Stating the value of the present research in conveying Move 3 Presenting the present work. This contrasts to Suryani (2014) study who investigated the rhetorical style of research article introductions in the field of Computer Engineering. They found that both steps occur only $20 \%$ each. This might be caused by the differing orientation of the disciplines within the same category of science. Therefore, there should be more academic investigations to address this discrepancy, whether there are intradisciplinary variations regarding the rhetorical styles of the introduction.

\subsection{Linguistic Realizations of the Moves}

This sub-section addresses the second research question regarding some linguistic features such as verb tense, sentence voice, metadiscourse, and citation practices to realize the rhetorical moves.

The findings showed that simple present tense was dominantly used in the introduction written by the authors from soft and hard sciences. No typical difference was identified between both groups. Some authors, however, preferred to use simple future tense, present continuous tense, and simple past tense in conveying Move 1 Establishing a territory and Move 3 Presenting the present work.

Regarding the sentence voice, active voice was more frequently used than passive voice. Passive voice was slightly more dominant to be used in conveying Move 3 Presenting the present work than in conveying Move 1 Establishing a territory and Move 2 Establishing a niche.

The analysis of metadiscoursal units of the moves was based on Hyland's (2009) categorization, focused on the use of interactional resources. The findings revealed that hedges were dominantly used not only in the soft-science introduction but also in the hard-science introduction. No typical difference was identified in the use of hedges between both groups. Most authors preferred the use of modal verbs such as can, will, must. Adverbs were also frequently employed to realize Move 1 Establishing a territory such as usually, possibly, considerably, often. In conveying Move 3 Presenting the present work, only model verb will was mostly used in the introductions. However, boosters were more dominantly used in the hard-science introductions than in their counterparts. Some types of boosters identified in the corpus were adjectives important, interesting, positive and adverbs truly, greatly, very.

Furthermore, Swales' (1986) classification of citation styles, i.e., integral and non-integral was utilized. First, citations were used by all authors to convey Move 1 Establishing a territory but appeared least in Move 3 presenting the present work. Second, there was no typical difference between soft- and hard-science introductions regarding the occurrence of citation style in which both integral and non-integral citation styles were used. Third, the authors from hard science preferred to use nonintegral citation style to present their present works.

The findings show that the nature of science does not necessarily influence the realizations of certain linguistic features to convey the rhetorical moves. The moves are typically realized by using present tenses in active forms. Citations typically occur in conveying Move 1 and Move 2 only. This is because Move 3 has moved to the introduction or brief description of the authors' works.

\section{CONCLUSION}

This study aimed to investigate how Indonesian authors from soft and hard sciences rhetorically organize their research article introductions and how the rhetorical moves are linguistically realized by both groups of authors. The findings demonstrate that all moves are considered obligatory to constitute an introduction, regardless of the disciplines. In the step level, the authors from soft and hard sciences have a common interest to announce their present works descriptively or purposively in manifesting Move 3 Presenting the present work. However, definitional clarifications and statement of value of the present work are only concerned by the authors from hard science. Regarding the linguistic realizations, the findings exemplify that no typical difference is evident because of different nature of science. This study reaches a conclusion that the nature of science does not necessarily affect the rhetorical organization of research article introductions.

The results of the present study may enrich the existing literature in the realm of academic writing for publication purposes. Hence, this study suggests that the literacy brokers of English for research publication purposes can develop more comprehensive learning resources that can capture disciplinary variations of rhetorical moves of research article introduction. Additionally, this study recommends more extensive studies on the influence of socio-cultural background of the authors on their rhetorical styles in writing research article introduction.

\section{ACKNOWLEDGMENTS}

This study was supported by a grant from the Research and Community Service Unit, Indonesia University of Education. The authors would like to express appreciation for all the support provided.

\section{REFERENCES}

Arsyad, S., Arono, N. F. N., Syaputra, J., Susilawati, N. F. N., Susanti, R., \& Musarofah, N. F. N. (2016). Tipe dan fungsi pengutipan di bagian pendahuluan 
artikel jurnal berbahasa Indonesia [Type and functions of citation in introduction section of Indonesian articles]. Linguistik Indonesia, 34(2), 163-178.

Baker, P. (2010). Corpus method in linguistics. In L. Litosseliti (Ed.), Research method linguistic (pp. 93116). London: Continuum.

Bazerman, C. (1981). What written knowledge does: three examples of academic discourse. Phylosophy of the Social Sciences 11, 361-387.

Chang, C-F., \& Kuo, C-H. (2011). A corpus-based approach to online materials development for writing research articles. English for Specific Purposes, 30, 222-234.

Hyland, K. (2009). Academic Discourse: English in a Global Context. London: Continuum.

Kanoksilapatham, B. (2005). Rhetorical structure of biochemistry research articles. English for Specific Purposes, 24(3), 269-292.

Samraj, B. (2002). Introduction in research articles: Variations across disciplines. English for Specific Purposes, 21(1), 1-17. https://doi.org/10.1016/S0889-4906(00)00023-5

Stoller, F. L., \& Robinson, M. S. (2013). Chemistry journal articles: An interdisciplinary approach to move analysis with pedagogical aims. English for Specific Purposes, 32(1), 45-57. https://doi.org/10.1016/j.esp.2012.09.001

Suherdi, D., Kurniawan, E., \& Lubis, A. (2020). A genre analysis of research article 'Findings and Discussion' sections written by Indonesian undergraduate EFL students. Indonesian Journal of Applied Linguistics, 10(1), 59-72. https://doi.org/10.17509/ijal.v10i1.24989

Suryani, A. (2014). Indonesian teacher education students' motivations for choosing a teaching career and a career plan (Doctoral dissertation). Monash University.

Swales, J. M. (1986). Citation analysis and discourse analysis. Applied Linguistics, 7(1), 39-56. https://doi.org/10.1093/applin/7.1.39

Swales, J. M. (1990). Genre analysis: English in academic and research settings. Cambridge: Cambridge University Press.

Swales, J. M. (2004). Research genres: Explorations and applications. Cambridge: Cambridge University Press.

Tessuto, G. (2015). Generic structure and rhetorical moves in English-language empirical law research articles: Sites of interdisciplinary and interdiscursive cross-over. English for Specific Purposes, 37, 13-26. https://doi.org/10.1016/j.esp.2014.06.002

Wannaruk, A., \& Amnuai, W. (2015). A comparison of rhetorical move structure of applied linguistics research articles published in international and national Thai journals. RELC Journal, 47 (2), 193211. https://doi.org/10.1177/0033688215609230 